\title{
Knockout confirmation for Hurries: rapid genotype identification of Trypanosoma cruzi transfectants by polymerase chain reaction directly from liquid culture
}

\author{
Monica Visnieski Alcantara ${ }^{1,2}$, Stenio Perdigão Fragoso ${ }^{1}$, Gisele Fernanda Assine Picchi+ \\ 'Laboratório de Biologia Molecular de Tripanossomatídeos, Instituto Carlos Chagas-Fiocruz, Curitiba, PR, Brasil \\ ${ }^{2}$ Departamento de Biologia Celular e Molecular, Universidade Federal do Paraná, Curitiba, PR, Brasil
}

\begin{abstract}
Gene knockout is a widely used approach to evaluate loss-of-function phenotypes and it can be facilitated by the incorporation of a DNA cassette having a drug-selectable marker. Confirmation of the correct knockout cassette insertion is an important step in gene removal validation and has generally been performed by polymerase chain reaction (PCR) assays following a time-consuming DNA extraction step. Here, we show a rapid procedure for the identification of Trypanosoma cruzi transfectants by PCR directly from liquid culture - without prior DNA extraction. This simple approach enabled us to generate PCR amplifications from different cultures varying from $10^{6}-10^{8}$ cells $/ m L$. We also show that it is possible to combine different primer pairs in a multiplex detection reaction and even to achieve knockout confirmation with an extremely simple interpretation of a real-time PCR result. Using the "culture PCR" approach, we show for the first time that we can assess different DNA sequence combinations by PCR directly from liquid culture, saving time in several tasks for $\mathrm{T}$. cruzi genotype interrogation.
\end{abstract}

Key words: culture PCR - knockout confirmation - Trypanosoma cruzi - colony PCR - genotype interrogation - transfectant culture

The generation of null mutants for specific genes has proven invaluable for elucidating gene function in several organisms (Bouche \& Bouchez 2001, Rong \& Golic 2001, Iiizumi et al. 2006, Kim et al. 2013). This approach is also known as gene knockout and can be achieved in a relatively simple manner: insertion of a DNA cassette that has a drug-selectable marker flanked by the coding sequence or the intergenic regions of the target gene via homologous recombination.

Gene knockout by homologous recombination is the conventional way of studying loss-of-function phenotypes in Trypanosoma cruzi - the protozoan parasite that causes Chagas disease - because RNA interference machinery is not functional in this organism (da Rocha et al. 2004).

Although T. cruzi homologous recombination is effective (Xu et al. 2009), it is important to verify whether the knockout cassette is at the correct locus. Current methods for confirmation depend on a DNA extraction step (Bernards et al. 1981, Karlinsey et al. 1989) that is time consuming. Although there are new, simpler alternatives to DNA extraction (Medina-Acosta \& Cross 1993, Rotureau et al. 2005), a fast, easy and efficient procedure that could enable the rapid identification of $T$. cruzi transfectants directly by polymerase chain reaction (PCR) analysis could be an advantage for routine molecular biology studies. As described for bacteria, yeasts

doi: $10.1590 / 0074-0276140010$

Financial support: CNPq, FIOCRUZ

MVA is supported by a CAPES fellowship.

+Corresponding author: giselepicchi@fiocruz.br

Received 11 January 2014

Accepted 18 March 2014 and algae (Packeiser et al. 2013), colony PCR could be the answer due to its quickness, simplicity and minimal amounts of required cells. Likely based on this idea, dos Santos et al. (2000) proposed a colony PCR method to screen $T$. cruzi colonies that has been selected on solid medium (Mondragon et al. 1999). However, although there are some advantages to growing transformants as colonies on agarose plates (Goldberg \& Chiari 1980, Wittner et al. 1982), liquid culture and limited dilution remain the preferred method.

All of this knowledge prompted us to develop a rapid approach for the genotype identification of T. cruzi transfectants by PCR directly from liquid culture. Thus, we describe here a method to obtain DNA samples for PCR analysis directly from liquid culture, essentially consisting of four simple steps: aliquoting up to $50 \mu \mathrm{L}$ of the $T$. cruzi transfectant culture together with the same volume of ultra pure water in a microtube, denaturing this mixture at $98^{\circ} \mathrm{C}$ for $15 \mathrm{~min}$, separating the cellular debris in a 1-min centrifugation step at top speed and using the nucleic acid-containing supernatant on the same day in PCR reactions.

In our very first attempt, we tested for amplification of the hygromycin resistance gene ( $\mathrm{Hyg})(1,037 \mathrm{bp})$ and an internal TcNUP-1 fragment (Nup1) (1,747 bp) in a $T$. cruzi transformant culture, demonstrating that is possible to PCR amplify DNA sequences directly from liquid cell culture (Fig. 1A). Next, we showed that it is also possible to verify the correct recombination of both selection marker cassettes in only one reaction using multiplex PCR (Fig. 1B).

Then, to verify whether our proposed method works despite the cell concentration of T. cruzi cultures, we tested seven concentrations, ranging from $10^{6}-10^{8}$ cells/ $\mathrm{mL}$, of the knocked out cultures for hygromycin and neo- 
mycin amplification (Fig. 2). Of note, we also obtained good amplifications from three-10-day-old cultures as well as from cultures that had been stored at $4^{\circ} \mathrm{C}$ for a week (data not shown).
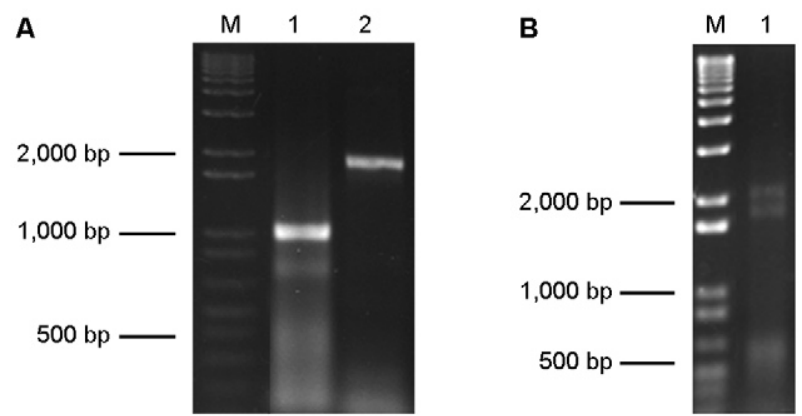

Fig. 1: validating the "culture-polymerase chain reaction" (PCR) approach. A: hygromycin resistance gene (Hyg) $(1,037 \mathrm{bp})$ and a fragment of the TcNUP-1 gene (Nup1) (1,747 bp) were successfully amplified by PCR from a transformant Trypanosoma cruzi culture; B: correct knockout cassette insertion was confirmed in a transformant T. cruzi culture by a multiplex PCR (ResF-ExtR) (1,990 and 1,758 bp) using both gene resistance forward primers (HygF and NeoF) and a reverse primer external to the cassette insertion (extR). PCR reactions were performed according standard protocols using $1 \mu \mathrm{L}$ of DNA sample obtained as described earlier. M: 1 kb Plus DNA Ladder (Invitrogen, Grand Island, NY, USA).

A
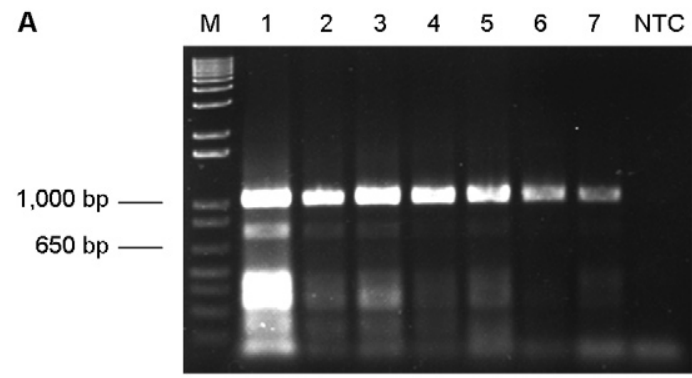

B
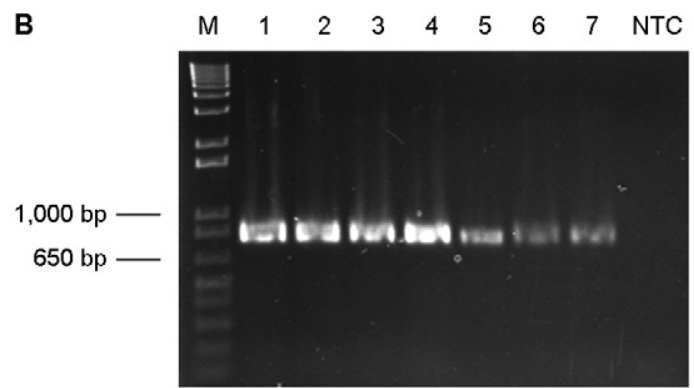

Fig. 2: obtaining DNA amplification from $10^{6}-10^{8}$ cells $/ \mathrm{mL}$ cultures. A: hygromycin resistance gene (1,037 bp) was successfully amplified from $1.2 \times 10^{8}(1), 6 \times 10^{7}(2), 3 \times 10^{7}(3), 1.5 \times 10^{7}(4), 7.5 \times 10^{6}(5), 3.8$ $\times 10^{6}(6)$ and $1.9 \times 10^{6}(7)$ cells $/ \mathrm{mL}$ transformant Trypanosoma cruzi cultures; B: neomycin resistance gene (805 bp) was successfully amplified from $6 \times 10^{7}(1), 3 \times 10^{7}(2), 1.5 \times 10^{7}(3), 7.5 \times 10^{6}(4), 3.8 \times 10^{6}(5)$, $1.9 \times 10^{6}(6)$ and $9 \times 10^{5}(7)$ cells $/ \mathrm{mL}$ transformant $T$. cruzi cultures. No template control (NTC) (water instead sample DNA) was included as negative control to confirm that primers had no DNA contaminations. Polymerase chain reactions were performed according standard protocols using $1 \mu 1$ of DNA sample obtained as described earlier. M: $1 \mathrm{~kb}$ Plus DNA Ladder (Invitrogen, Grand Island, NY, USA).
Although the proposed approach for knockout confirmation is better than what is available to date, gel electrophoresis results are required for visualisation. As an alternative method to investigate a large number of cultures with no gel needed, we propose a simple analysis using real-time PCR.

In the first test, we did not observe good amplification signals using samples prepared as if they were to be used for conventional PCR (data not shown). Assuming that this test failed because PCR inhibitors are present in the liver infusion tryptose culture medium and real-time PCR is more sensitive to them, we decided to evaluate whether dilutions of the samples could reduce inhibitors, enabling correct amplifications. Indeed, compared with the results obtained for genomic DNA, we conclude that the samples must be diluted to avoid reaction inhibition by the culture medium components. Furthermore, we propose that a 1:200 dilution should be used for real-time PCR reactions (instead of the 1:1 dilution for conventional PCR) because it was the best result, with a smaller cycle threshold $(\mathrm{Ct})$ deviation (Supplementary data). Thus, requiring no standard curve and using only the $\mathrm{Ct}$ information, we were able to corroborate the use of real-time PCR results for the determination of knockout cassette insertion in the cultures of different transformants (Fig. 3).

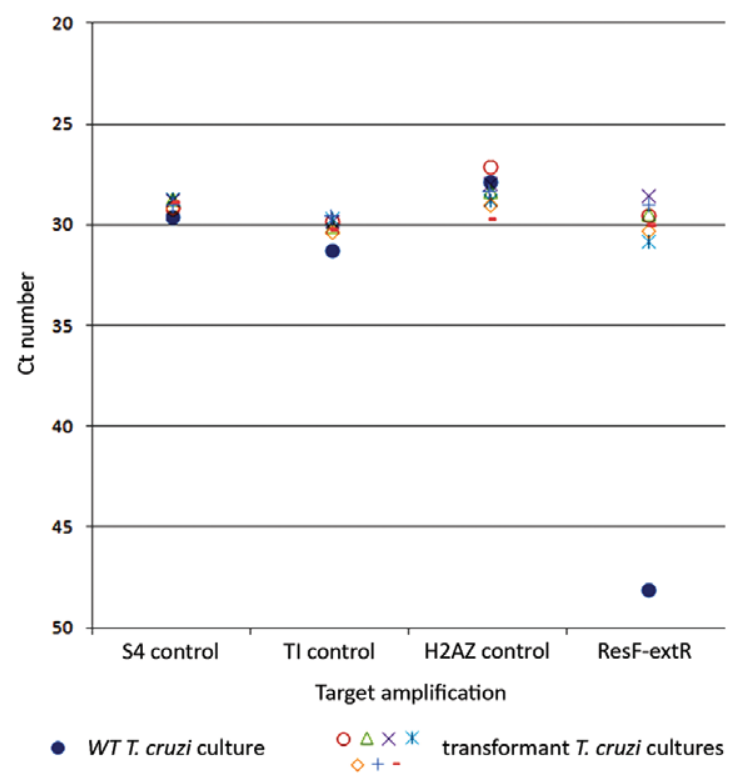

Fig. 3: confirming knockout cassette insertion at the right locus by real-time polymerase chain reaction (PCR). Graphic representation of cycle threshold $(\mathrm{Ct})$ number obtained after real-time PCR reaction allowing genotype comparison since all tested samples were obtained from roughly $2 \times 10^{7}$ cells $/ \mathrm{mL}$ cultures. As expected, amplification of $40 \mathrm{~S}$ ribosomal protein $\mathrm{S} 4$ ( $\mathrm{S} 4$ control), triosephosphate isomerase (TI control) and histone H2AZ (H2AZ control) genes was about the same in wild type (WT) and all seven different transformant Trypanosoma cruzi cultures. Hygromycin knockout cassette was inserted at the right locus since samples from transformant population cultures were positives when amplified using a forward primer internal to the construction (IR2intF) and a reverse primer external to the cassette insertion (extR). No template control (data not shown) was included as negative control. Real-time PCR reactions were performed according standard protocols using $2 \mu \mathrm{L}$ of DNA sample obtained as described earlier. 
We describe herein a powerful approach because it can be utilised in the confirmation of plasmid presence for ectopic expression assays in addition to being used in cassette insertion verification for knockout assays. Moreover, this method could be used to quickly distinguish between T. cruzi cultures of different genotypes or even between different strains (Liarte et al. 2009).

In fact, the major advance proposed here is a very simple method that enables one to obtain - quickly and precisely - answers to questions regarding DNA directly from liquid cultures, without the need for previously extracted DNA. That is, we demonstrate the feasibility of a valuable tool that saves bench time for several $T$. cruzi genotype investigations.

\section{ACKNOWLEDGEMENTS}

To Alejandro Correa and Alexandre DT Costa, for paper revision.

\section{REFERENCES}

Bernards A, Van der Ploeg LH, Frasch AC, Borst P, Boothroyd JC, Coleman S, Cross GA 1981. Activation of trypanosome surface glycoprotein genes involves a duplication-transposition leading to an altered 3' end. Cell 27: 497-505.

Bouche N, Bouchez D 2001. Arabidopsis gene knockout: phenotypes wanted. Curr Opin Plant Biol 4: 111-117.

da Rocha WD, Otsu K, Teixeira SM, Donelson JE 2004. Tests of cytoplasmic RNA interference (RNAi) and construction of a tetracycline-inducible T7 promoter system in Trypanosoma cruzi. Mol Biochem Parasitol 133: 175-186.

dos Santos WG, Metcheva I, Buck GA 2000. Colony polymerase chain reaction of stably transfected Trypanosoma cruzi grown on solid medium. Mem Inst Oswaldo Cruz 95: 111-114.
Goldberg SS, Chiari E 1980. Growth and isolation of single colonies of Trypanosoma cruzi on solid medium. J Parasitol 66: 677-679.

Iiizumi S, Nomura Y, So S, Uegaki K, Aoki K, Shibahara K, Adachi N, Koyama H 2006. Simple one-week method to construct genetargeting vectors: application to production of human knockout cell lines. Biotechniques 41: 311-316.

Karlinsey J, Stamatoyannopoulos G, Enver T 1989. Simultaneous purification of DNA and RNA from small numbers of eukaryotic cells. Anal Biochem 180: 303-306.

Kim HS, Li Z, Boothroyd C, Cross GA 2013. Strategies to construct null and conditional null Trypanosoma brucei mutants using Crerecombinase and LoxP. Mol Biochem Parasitol 191: 16-19.

Liarte DB, Murta SM, Steindel M, Romanha AJ 2009. Trypanosoma cruzi: multiplex PCR to detect and classify strains according to groups I and II. Exp Parasitol 123: 283-291.

Medina-Acosta E, Cross GA 1993. Rapid isolation of DNA from trypanosomatid protozoa using a simple 'mini-prep' procedure. Mol Biochem Parasitol 59: 327-329.

Mondragon A, Wilkinson SR, Taylor MC, Kelly JM 1999. Optimization of conditions for growth of wild-type and genetically transformed Trypanosoma cruzi on agarose plates. Parasitology 118: 461-467.

Packeiser H, Lim C, Balagurunathan B, Wu J, Zhao H 2013. An extremely simple and effective colony PCR procedure for bacteria, yeasts and microalgae. Appl Biochem Biotechnol 169: 695-700.

Rong YS, Golic KG 2001. A targeted gene knockout in Drosophila. Genetics 157: 1307-1312.

Rotureau B, Gego A, Carme B 2005. Trypanosomatid protozoa: a simplified DNA isolation procedure. Exp Parasitol 111: 207-209.

Wittner M, Squillante L, Nadler JP, Tanowitz HB 1982. Trypanosoma cruzi: colony formation and clonal growth in agar. Exp Parasitol 53: $255-261$.

Xu D, Brandan CP, Basombrio MA, Tarleton RL 2009. Evaluation of high efficiency gene knockout strategies for Trypanosoma cruzi. BMC Microbiol 9: 90 